\title{
What do Our Faculty Use? An Interdisciplinary Citation Analysis Study
}

Corresponding Author: Lea Currie, University of Kansas Libraries

\author{
Watson Library \\ 1425 Jayhawk Blvd. \\ Lawrence, KS 66045 USA \\ lcurrie@ku.edu \\ (785) 864-8897 \\ Amalia Monroe-Gulick, University of Kansas Libraries \\ Watson Library \\ 1425 Jayhawk Blvd. \\ Lawrence, KS 66045 USA \\ almonroe@ku.edu \\ (785) 864-3362
}




\begin{abstract}
During the fall of 2012 and spring of 2013, two librarians from the University of Kansas Libraries conducted a citation analysis of faculty publications in three broad disciplinary areas: humanities, social sciences, and science. The main purpose of research was to find out if the library provides adequate support to faculty researchers. The authors confirmed that KU Libraries provides access to the majority of items used by campus researchers. In addition, the findings will be used in collection management decisions, such as demand driven acquisition. Finally, the authors analyzed additional citation analysis studies in order to establish external benchmarks for their results.
\end{abstract}

\title{
Introduction
}

Librarians have long prided themselves on making data-driven collection development decisions. Ever since usage statistics for electronic resources were introduced by vendors and publishers, the University of Kansas (KU) Libraries have maintained a staff intranet web site with usage data for databases and electronic journals. This usage data is accessible to librarians and valuable when making renewal decisions. Librarians collect circulation statistics, including browse statistics for items that are used within the libraries and re-shelved without being checked out. Subject librarians annually review their continuations payment history, which includes the prices of subscriptions over the previous three years, and circulation statistics when making journal subscription renewal decisions. Circulation statistics and shifts in the number of students and faculty in research programs are also reviewed annually before decisions are made for allocating funds for the purchase of monographs. In 2010, KU subject librarians participated in a year-long project to collect overlap data from peer libraries using the OCLC Collection Analysis Tool, utilizing these statistics and monograph titles lists to inform collection development decisions. Yet, no attempt was ever made to collect data from what was actually being cited by the KU researchers.

In an effort to prove that the KU Libraries provide a valuable service to faculty by collecting the appropriate materials for their research, the authors decided to conduct an extensive citation analysis of the works cited in faculty-authored journal articles. By collecting a sampling of citations from journal articles written by KU faculty and checking them against the library holdings, the authors hypothesized that the KU Libraries provide a significant number of the resources that faculty use for their research. While the study was being designed, more detailed questions about faculty citation patterns arose, including:

1. What formats (books, journals, etc.) are used by faculty in the broad disciplines of social sciences, sciences, and humanities?

2. What is the age of the cited materials?

3. Are we providing access to the cited journal articles through subscription journal packages or aggregator databases? 
4. Who are the most cited publishers?

5. Do citation patterns vary among the broad disciplinary areas?

6. Are faculty citing resources from their own field of study or are they citing resources from other disciplines?

7. Do current budget allocations adequately support the most frequently used formats, publishers, and subject areas?

The authors began this project with the assumption that the faculty in the sciences cite more journals than monographs and that they use newer materials than faculty in the humanities. It was also assumed that social scientists use more journals than monographs, but that the humanists use more monographs and cite older materials than the other broad subject disciplines. In some cases, these assumptions were correct, but in other cases, the results were unexpected.

\section{Selected Literature Review}

The academic library literature offers many methodologies for conducting citation analysis studies. Hoffman and Doucette ${ }^{i}$ reviewed the citation analysis literature published between the years 2005-2010. In reviewing the methodologies of the citation analysis studies, the authors learned that there are many variables to consider when conducting citation analysis research, including selecting a category of users, defining the types of publications, and defining the date range of publications. The researchers of the studies reviewed in this article used a variety of software and databases to help them analyze the data they collected. Most were interested in the frequency of citations to journal and monograph titles. Library holdings were another important component of the studies. Hoffman and Doucette also discovered that sampling was the most effective method for working with a manageable number. Saturation was another method of collecting data by increasing the number of publications until it was determined that analysis of additional citations would not significantly change or add to the results. Watson ${ }^{\mathrm{ii}}$ suggested that both students and faculty were valid targets for citation studies, but large research institutions with a large graduate population may benefit more from a faculty analysis. Faculty citation studies offered a number of conveniences to researchers as opposed to student studies. Lists of publications were generally easier to obtain since many departments on campus maintain curricula vitae on departmental web sites. Privacy was also less of an issue since faculty tend to publish in peer reviewed publications intended for dissemination, whereas student papers are intended for a limited audience. The authors of this article also found that faculty was the most convenient population on campus to study and sampling to a saturation point was the most time efficient method of collecting data.

When library researchers have analyzed citations from faculty, they most frequently have selected faculty in the sciences. The authors selected faculty in the sciences during the initial stages of the project, but soon determined that it would be more valuable to compare science faculty citations to faculty in the social sciences and humanities. The results reported in other 
studies were also used as comparative data for the numbers in this study. Choinski ${ }^{\text {iii }}$ chose to examine the journal literature that pharmacy faculty at the University of Mississippi published to determine the most frequently used journal titles, their subject areas, the age of the citations relative to the source articles, and the major publishers of those journals. The results were derived from 251 source articles published in 124 journals. LaBonte ${ }^{\mathrm{iv}}$ used a citation analysis to learn whether the research needs of 60 faculty affiliated with the California NanoSystems Institute were being met by the Sciences-Engineering Library at the University of California. Articles published by the faculty between the years 2002-2003 were collected and analyzed using information obtained from the Science Citation Index. The citation analysis was derived from the journals in which they were published and the journals where cited articles were published. The journal titles and years of publication were recorded, as well as each journal cited eleven or more times (containing the top third of the citations), which were then compared to holdings in the library catalog. The goal of the study was to develop a core list of journals and identify journals that should be added to the collection. LaBonte was pleased to discover that the library provided access to $98 \%$ of the journals cited.

University of Arkansas science faculty publications were also the source for a citation analysis. Salisbury and $\mathrm{Smith}^{\mathrm{V}}$ used Web of Knowledge to identify journals in which their faculty published and the journals that they cite in their publications. They also determined the extent to which their faculty was publishing in journals from large journal subscription packages. Faculty publications totaling 2,681 were retrieved from Web of Science, as well as 75,912 citations from the faculty's publications. These data elements were useful when making decisions to renew journal packages and cancel low use journals.

Only a few librarians have used faculty citations from multiple disciplines for citation analysis. Wilson and Tenopir ${ }^{\mathrm{vi}}$ took a sample of faculty journal publications with their cited references and used the results of a faculty survey of reading patterns to evaluate the collections in an academic library. A sample of 100 source journals were determined and 3,095 citations from these publications were downloaded into a spreadsheet. The type of format for each of the citations was noted as a journal, monograph, or other and all of the journals were checked for holdings in the library collections. Faculty reported through the survey that they were not likely to have personal journal subscriptions and at least half of their readings were from library sources.

A vast majority of collection analysis is conducted by collecting data from dissertations and theses submitted by graduate students. Many of these studies collect data from students in the science and technology disciplines. Williams and Fletcher ${ }^{\text {vii }}$ used masters' theses in engineering, identifying 250 sources with 9,340 citations. Each citation was recorded for format and age of publication. Kuruppu and Moore ${ }^{\text {viii }}$ used graduate research in agricultural and biological sciences to identify citation patterns. The study covered dissertations submitted between 1997-2006 at Iowa State University. A random sample of 154 dissertations was examined and most of the research cited in the sample was from journals. Vallmitjana and 
Sabate ${ }^{\text {ix }}$ studied citations within chemistry dissertations to ascertain what types of documents were most frequently used in the research process, the most frequently consulted journals, and the obsolescence rate of the journals. The results obtained from 4,203 citations revealed that the most frequently used publications were from science journals. Citation analysis in the sciences revealed that journal use far exceeds the use of monographs overall.

Some librarians use citation analysis to compare two different disciplines. Feyereisen and Spoiden ${ }^{\mathrm{x}}$ analyzed citations from a large number of masters' and doctoral theses from psychology and education sciences students. The researchers were surprised by the high number of monograph citations. They found very similar results for both disciplines. Fuchs, Thomsen, Bias, and Davis, Jr. ${ }^{\mathrm{xi}}$ selected 26 dissertations submitted between 1997-2002 by civil engineering and educational psychology students at the University of Texas at Austin. The investigators collected the first 30 citations from each dissertation. For each citation, the work's format was identified and additional details were recorded, including date of publication, title, publisher, and whether the resource was currently held at the library and if so, in print or electronic or both. The number of citations totaled 3,120. Journals served as the primary source for each group. Monographs retained the second position for format of choice.

Librarians also use dissertations from a cross-section of multiple disciplines for citation analysis. Smith ${ }^{\text {xii }}$ used a sample of 13 theses and 17 dissertations submitted in 2001 and 1991 at the University of Georgia. The same number was used for both years. Citations were coded by format and library holdings were determined. A total of 3,363 citations were examined from the theses and dissertations. Journals were cited most frequently (54\% in 1991 and 48\% in 2001). Monographs were cited with the second greatest frequency (37\% in 1991 and 38\% in 2001). Arts and humanities and the sciences each had one dominant format. Approximately $75 \%$ of the arts and humanities citations were monographs in 1991 and 2001, whereas the bulk of citations in the sciences were journals (79\% in 1991 and 64\% in 2001). Smith found that citation patterns in education and the social sciences were more balanced. For these two disciplines, journals were the most cited in both 1991 and 2001, making up 60\% of the social science citations and almost half of the education citations. However, monographs were also very important, accounting for about a third of the citations in education and the social sciences.

Kanyongo and Helm ${ }^{\text {xii }}$ focused their study on dissertations submitted at the University of Notre Dame from 2005-2007. The dissertations were produced in 19 departments and the citations from the graduate research produced 39,106 citations. For the 27,652 discrete titles, the librarians searched the library catalog to determine library holdings. No "point of time" ownership was taken into account due to time constraints. These multidisciplinary studies gave a clearer picture of journal and monograph use across the disciplines.

Occasionally, librarians find undergraduate research papers useful for citation analysis. Leiding ${ }^{\text {xiv }}$ examined a sample of 101 undergraduate honors theses from 1992-2002 to determine the adequacy of the library collections for undergraduate research. Twenty two academic 
departments were represented by the sample, with a mix of sciences, arts and humanities, and social sciences. The total number of citations was 3,564.This study sought to determine changes in the trends in journal use and the impact of the internet on citation behavior. Citations from the selected theses were checked to determine library holdings and format. The study found that the overall reliance on journals and monographs was fairly equal (41.4\% journals and $36.3 \%$ monographs). The internet did not seem to have an effect on the use of monographs over time, but the use of journals did increase slightly after the internet was introduced. This study suggested that undergraduate use patterns closely followed those of faculty and graduate students.

\section{Methodology}

Three broad disciplinary areas, humanities, social sciences, and sciences, were selected for this project, with three departments chosen within each area. For the humanities, faculty citations were analyzed from art history, English, and philosophy. The social science disciplines selected were economics, political science, and psychology. From the science disciplines, ecology and evolutionary biology, geology, and physics were analyzed. These departments were selected because the authors assumed that they could achieve a contrasting sample within each broad disciplinary area. Faculty from each department were randomly selected. Next, student assistants collected a list of faculty publications from their curriculum vitae, which are publicly available on departmental web sites. The parameters for this study were journal articles published 2005 to the present. The sample size differed among each broad area because of the large variance in the number of citations. After randomizing the citations using Excel, the following sample sizes were used:

Science citations: $15 \%(1,511$ out of 10,294$)$

Social Science citations: $36 \%(1,246$ out of 3,463$)$

Humanities citations: $59 \%$ (465 out of 784)

Cumulative sample size: $22 \%(3,222$ out of 14,541$)$

The total number of citations gathered from all faculty publications was 14,541 and the resulting sample was 3,222 (22\%). The science disciplines comprised $47 \%$ of the citations, the social sciences $39 \%$, and the humanities represented $14 \%$ of the sample.

Once the samples from each department were identified, they were combined for analysis. The citations then were analyzed to find specific data. The authors recorded the following data for each citation:

1. Publisher

2. Publication date

3. Format (journal article, book, report, etc.) 
4. Call number

5. KU availability

6. Print access

7. Electronic access

8. Journal package access

9. Aggregator database access

All data was recorded in Excel spreadsheets. The next step was to analyze the citations by broad disciplinary area followed by a cumulative analysis of all citations.

\section{Limitations}

With any citation analysis project, there are limitations. One of the problems the authors encountered during the project was the currency of the curriculum vitae of the faculty members. The curriculum vitae publically available through department web sites may not be up to date or complete. Analyzing older publications may not reflect the current research patterns of faculty. Limiting the citation analysis to journal articles does not allow for a comprehensive analysis of faculty in the humanities, who typically publish more monographs than journal articles. In addition, human error in data collection could also affect the accuracy of results. The difference in sample sizes is a methodological limitation; however, time constraints for the authors made these variations necessary. Time constraints were also a factor when checking the holdings at the time the research was conducted by the faculty. The authors did not have time to check to make sure the citation was accessible at the "time of publication," so they operated under the assumption that, if the libraries currently provided access, they probably provided access at the time the article was being researched.

\section{Results:}

\section{Cumulative Analysis}

The average publication date of the citations in the entire sample was 1991 with a median publication date of 1999. The oldest item cited was from 1681 and the newest item was from 2012. Journal citations comprised $66 \%$ of the total citations and book citations comprised $28 \%$ of the total citations, with "other" comprising the remainder (including conference proceedings reports, web sites, etc.)

\section{KU Holdings}

From the sample of 3,222 citations, the authors found that KU Libraries provided access to $86 \%$ of the items cited by faculty. 


\section{Print Only Holdings}

Out of the 2,781 cited items held by KU, 958 are available only in print (34\%). The average publication date of print-only holdings is 1989 with a median publication date of 1994 . Book citations made up $64 \%$ of the print-only citations.

\section{Electronic Holdings}

The cited items held by KU that are only available electronically total 584 (21\%). Of these, $64 \%$ were journal citations. The average publication date of electronic-only items was 1994 with a median publication date of 2004.

\section{Print/Electronic Holdings}

Of all of the cited items held by KU, 1,246 (45\%) are available both in print and electronically. The vast majority of the duplicated items are journal articles at $93 \%$. Only $5 \%$ of book citations are available in both print and electronic formats. The average publication date of duplicative access is 1994 with a median publication date of 1998.

\section{Cumulative Analysis: Journals}

When all citations from all of the disciplines are combined, journal articles comprise $66 \%$ of the total. KU provides electronic and/or print access to $92 \%$ of the journal articles cited (see Chart 1). Twenty five percent of the journals are available only in electronic format, $24 \%$ are available only in print format, and $52 \%$ are available in both electronic and print formats. The citations from the science disciplines comprise $55 \%$ of all journal citations, the social science disciplines comprise $40 \%$ of all journal citations, and the humanities disciplines comprise only $6 \%$ of all journal citations.

\section{Chart 1: Total Journal Citations Access by Disciplinary Area}

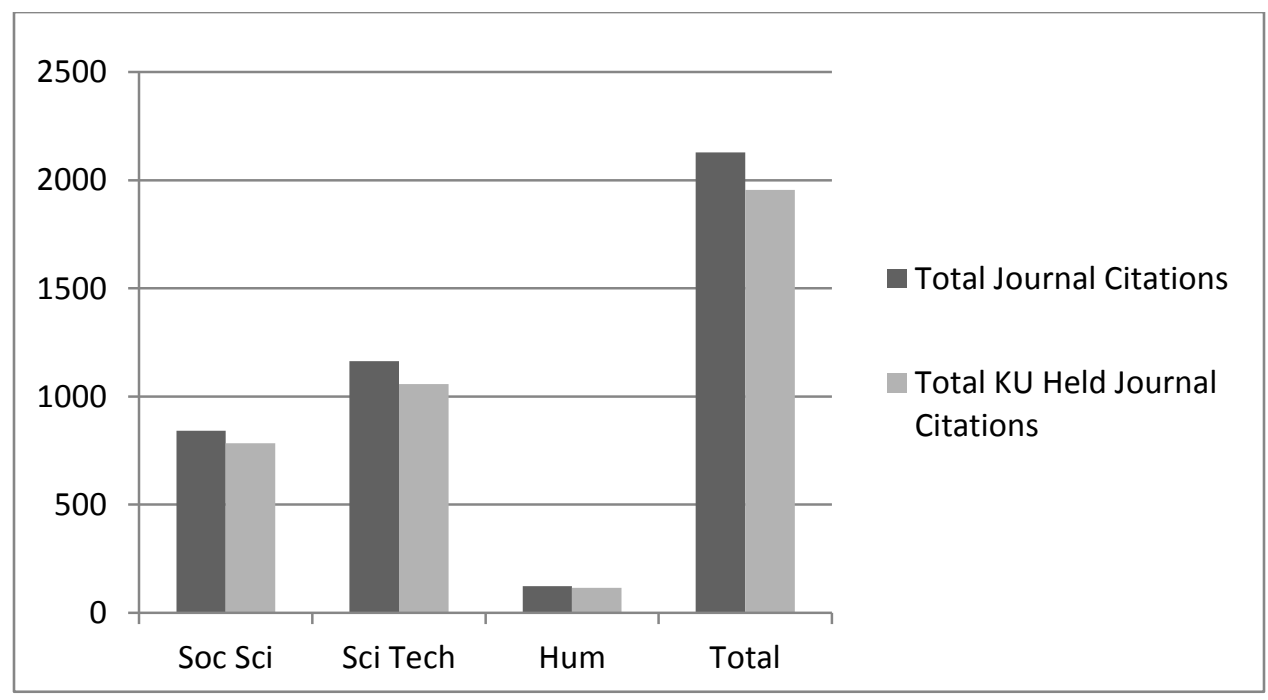


Of the electronically available journal articles, $67 \%$ are accessible through a journal package and $38 \%$ are available in one or more aggregator databases. The predominant publishers for all cited journal articles are Elsevier (10\%) and Wiley-Blackwell (8\%).

\section{Cumulative Analysis: Books}

Book citations comprise $28 \%$ of the total citations sampled from faculty publications in the three disciplinary areas. KU provides access to $80 \%$ of the books cited in print and/or electronic formats (see Chart 2). The average publication date of all book citations is 1991 with a median publication date of 1998. Books in print format comprise $87 \%$ of the KU held citations, with $9 \%$ of the book citations duplicated in electronic and print, and $3 \%$ available only in electronic format.

\section{Chart 2: Total Book Citations by Disciplinary Area}

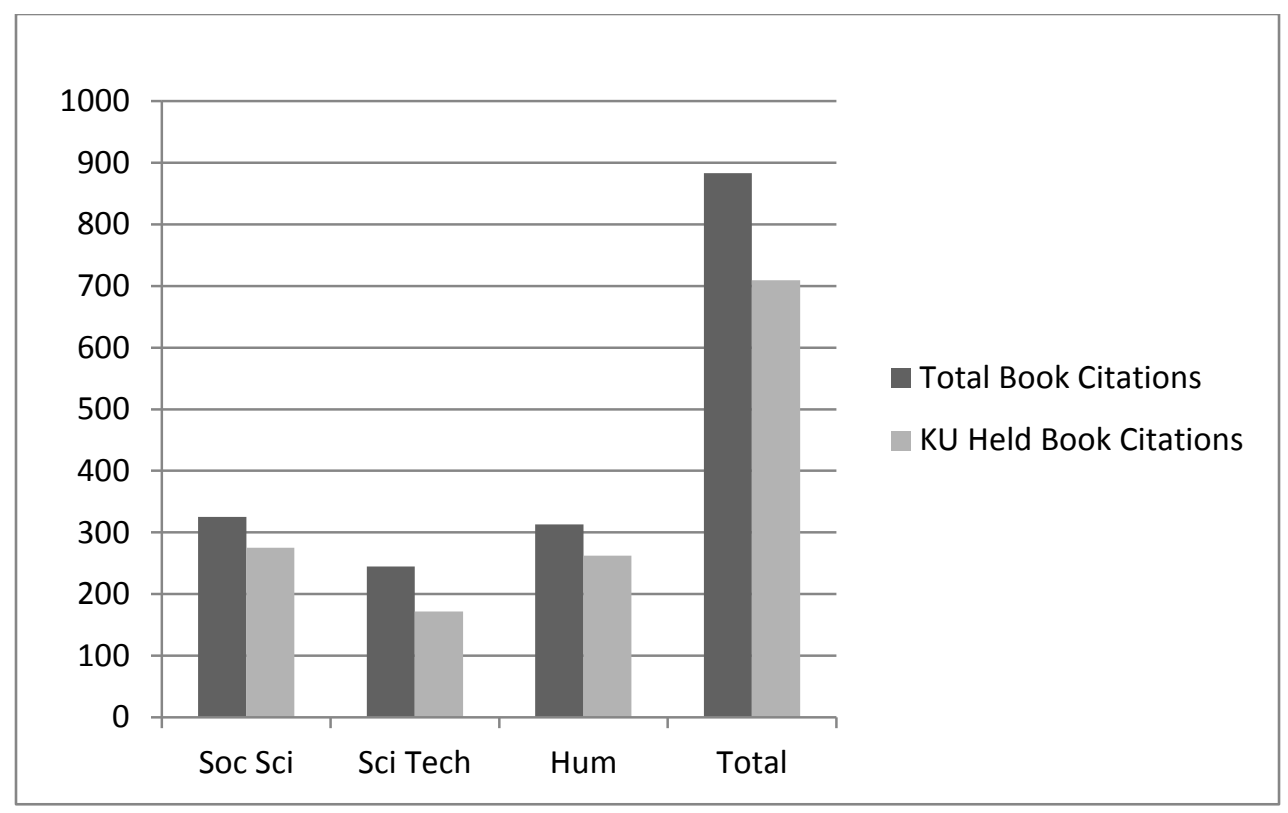

Sixty one citations (7\%) came from books published by Cambridge University Press, followed by Oxford University Press with 43 citations (5\%) and Wiley-Blackwell with 37 citations (4\%). 


\section{Chart 3: Format Usage by Broad Disciplinary Area (\%)}

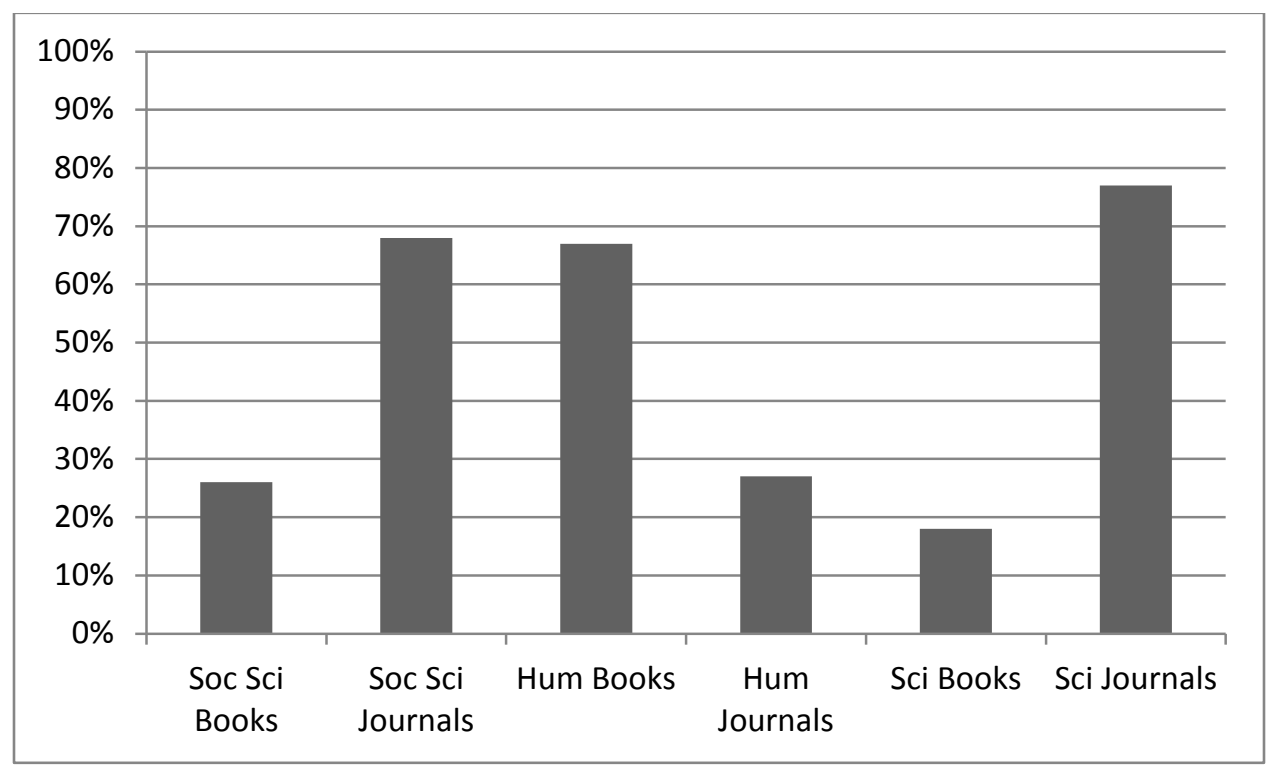

\section{Cumulative Analysis: Items Not Held by KU}

KU Libraries does not provide access to 441 (13\%) of the total citations sampled from faculty publications. Books comprise $41 \%$ of these items and journal articles comprise $39 \%$, with the remainder falling under the "other" category (see Chart 4). The average publication date of items not held by KU is 1988 with a median publication date of 1999 . Of the items not held by $\mathrm{KU}, 50(12 \%)$ are written in languages other than English. Items within the Q Library of Congress call number range comprise $29 \%$ of items not held by KU, which corresponds to the larger percentage of science citations in the sample (See Chart 5).

\section{Chart 4: \% of Items Not Held by KU (format and discipline)}

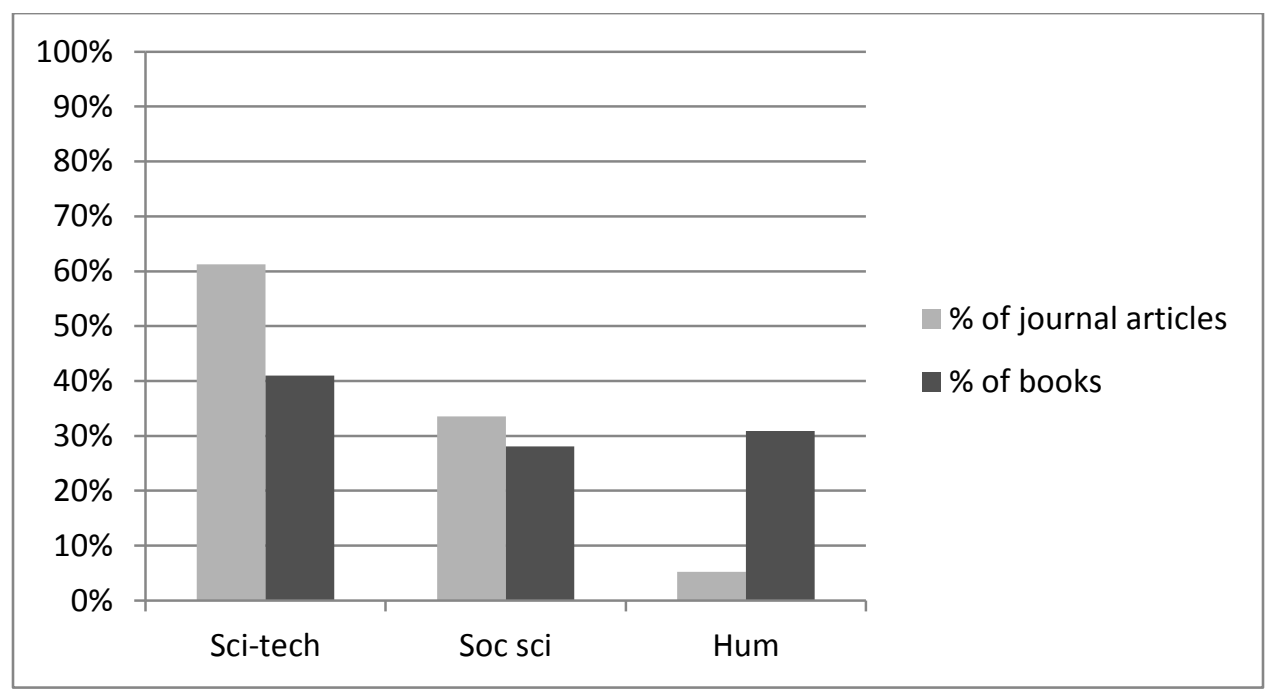




\section{Chart 5: \% of Items Not by Held by KU (call number ranges)}

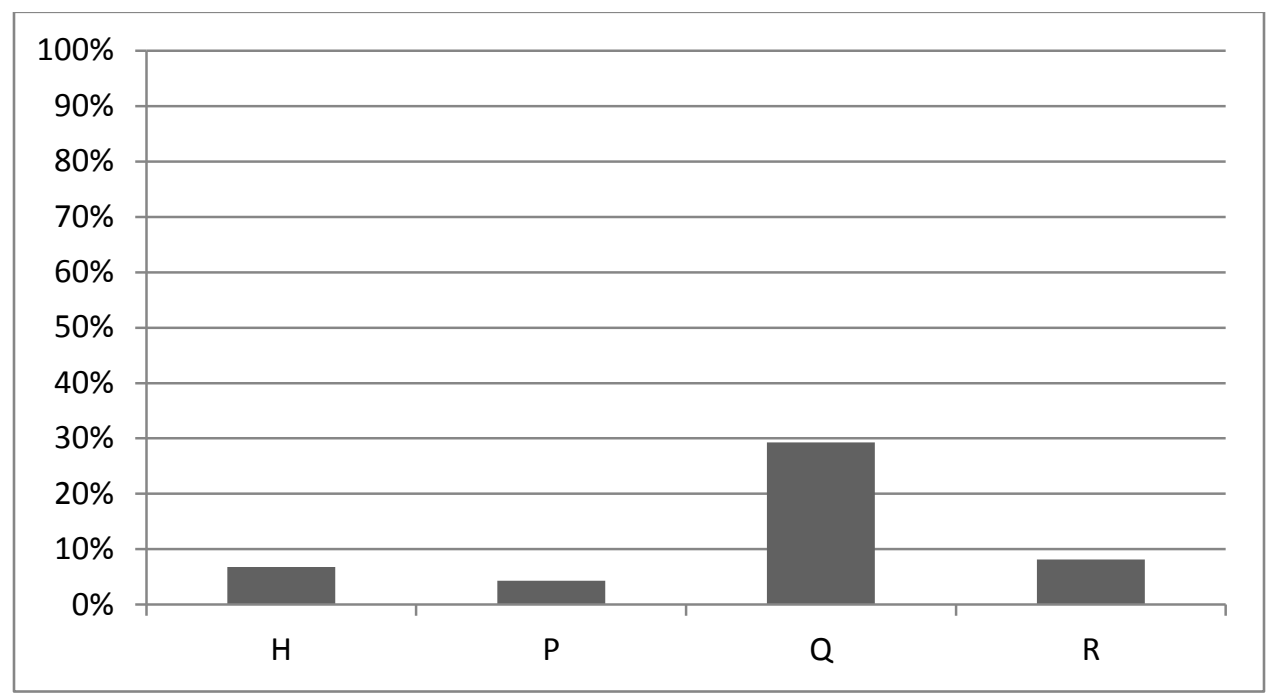

\section{Social Science Analysis}

Faculty publications from three social science disciplines were sampled for this project: economics, political science, and psychology (see Table 1).

Table 1: Total Sample Citations by Discipline

\begin{tabular}{|l|l|l|l|}
\hline & Econ & Pol Sci & Psy \\
\hline $\begin{array}{l}\text { Total Sample } \\
\text { Citations for } \\
\text { Analysis }\end{array}$ & 277 & 446 & 523 \\
\hline $\begin{array}{l}\text { \% of Citations in } \\
\text { Cumulative Sample }\end{array}$ & $22 \%$ & $36 \%$ & $42 \%$ \\
\hline
\end{tabular}

The average publication date of all social science citations was 1996, with a median publication date of 1998. The oldest item cited was from 1888 and the newest item cited was from 2012 . KU held $89 \%$ of the items cited by faulty in the three selected disciplines. $32 \%$ of the KU-held items were available in print, $18 \%$ were available in electronically, and $50 \%$ of the items were available in both print and electronic formats.

\section{Social Science Analysis: Books}

Out of the 1,246 social science citations analyzed, 325 were book citations (26\%). The average publication date was 1996, with a median publication date of 1998. KU provided access in print and/or electronic formats to 275 of the cited books (85\%). The availability of books in electronic format was limited; only 37 (13\%) cited books were available electronically (See Chart 6). 


\section{Chart 6: Book Access by Format (\%)}

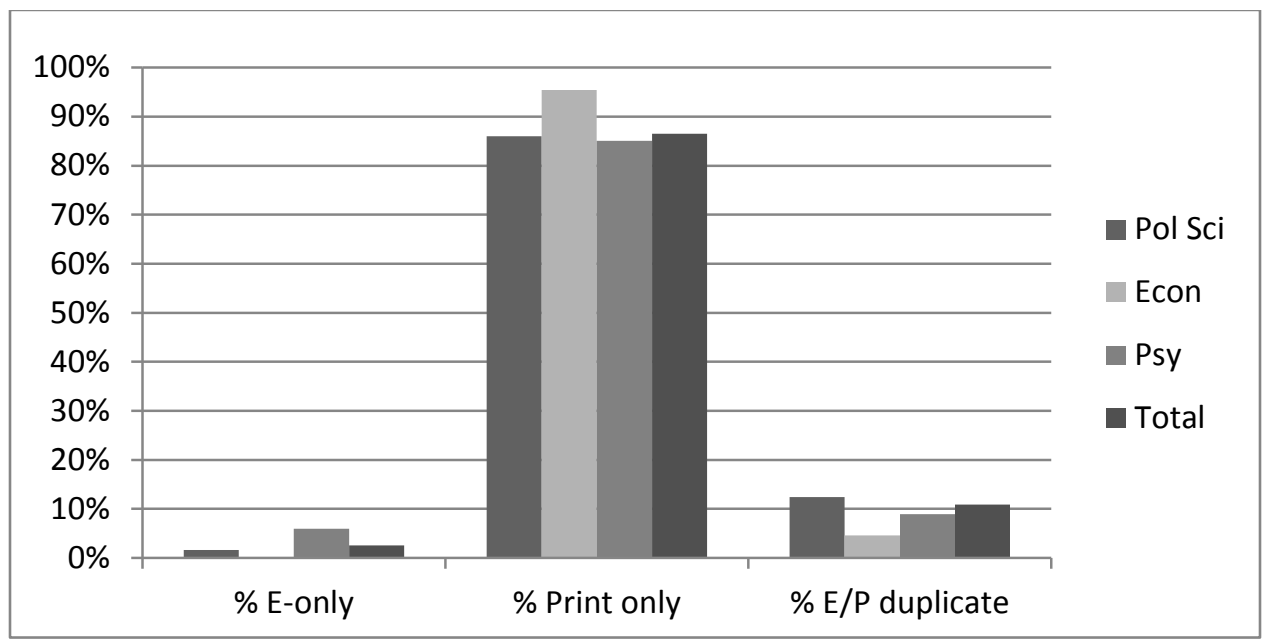

The publisher with the most cited items in the social sciences was Cambridge University Press, with 29 titles or $9 \%$.

\section{Social Science Analysis: Journals}

From the total social science sample of 1,246, 842 were journal article citations $(68 \%)$. The average publication date of the journal articles was 1996, with a median publication date of 1999. KU provided access to $784(93 \%)$ of the journal articles cited. Eighty six percent were available electronically (See Chart 7). The average publication date of electronic only accessible articles was 1999 and the average publication date of duplicated articles was 1995, which is equivalent to print-only articles.

\section{Chart 7: Social Science Journal Access by Format (\%)}

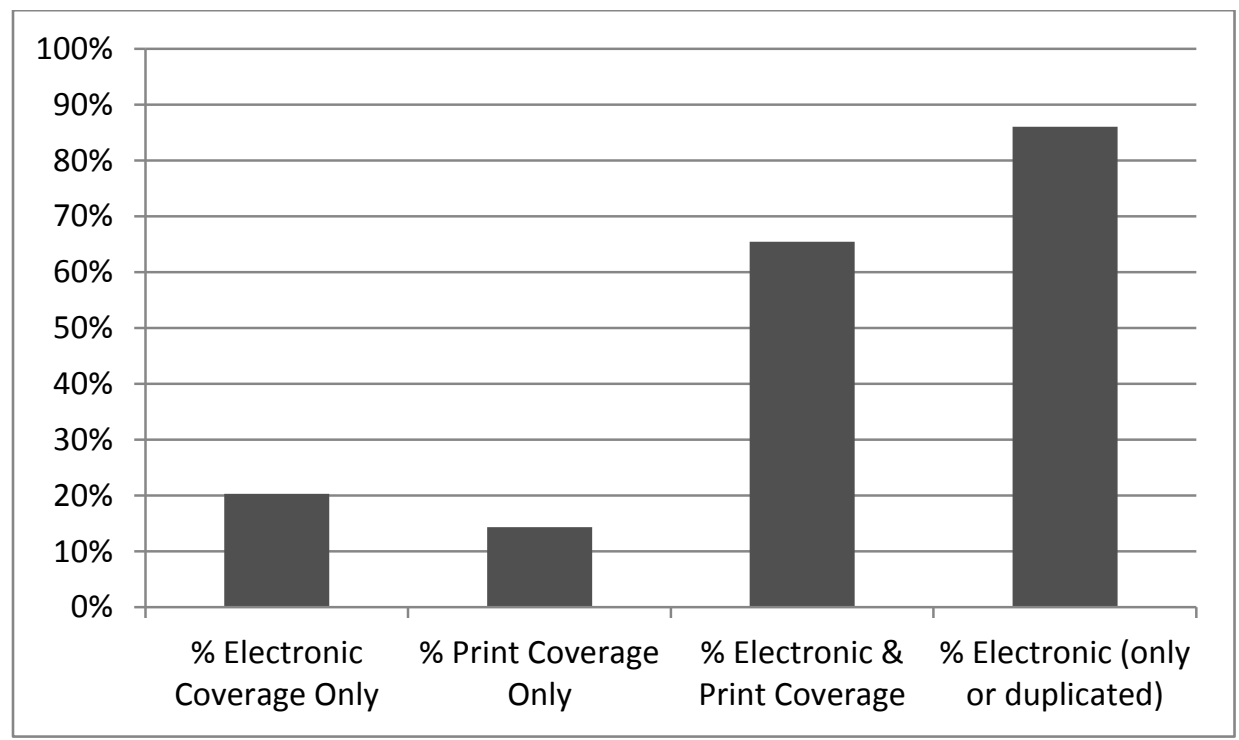


For those articles available electronically, 59\% could be accessed through a journal package and $45 \%$ could be accessed through one or more aggregator databases. The predominant publishers in the social science journal citations are Elsevier and Wiley-Blackwell. These two companies together publish $15 \%$ of titles cited by social science faculty at KU.

\section{Social Science Analysis: Items not held by KU}

KU did not provide access to 139 items cited by social science faculty (11\%). The average publication date for these items was 1999, with a median publication date of 2002. Journal articles comprised $42 \%$ of the items not held by KU and books comprised $36 \%$.

\section{Humanities Analysis}

Faculty publications from three humanities disciplines were sampled for this study: art history, English, and philosophy (see Table 2).

\section{Table 2: Total Sample Citations by Discipline}

\begin{tabular}{|l|l|l|l|}
\hline & $\begin{array}{l}\text { Art } \\
\text { History }\end{array}$ & English & Philosophy \\
\hline $\begin{array}{l}\text { Total Sample } \\
\text { Citations for } \\
\text { Analysis }\end{array}$ & 105 & 285 & 75 \\
\hline $\begin{array}{l}\text { \% of Citations in } \\
\text { Cumulative Sample }\end{array}$ & $23 \%$ & $61 \%$ & $16 \%$ \\
\hline
\end{tabular}

The average publication date of all humanities citations was 1986, with a median publication date of 1997. KU provided access to $85 \%$ of all items cited by humanities faculty. The oldest item cited was from 1681 and the newest item cited was from 2012. Of the total citations, 66\% were available only in print, $8 \%$ only electronically, and there was a print/electronic duplication rate of $26 \%$.

\section{Humanities Analysis: Books}

Book citations comprised $67 \%$ of the total humanities sample, which, not surprisingly, is significantly higher than the cumulative sample percentage of $28 \%$ books. The overall average publication date of humanities books was 1985, with a median publication date of 1997. Print was the dominant access format of humanities books at 90\% (see Chart 8). 


\section{Chart 8: Book Access by Format (\%)}

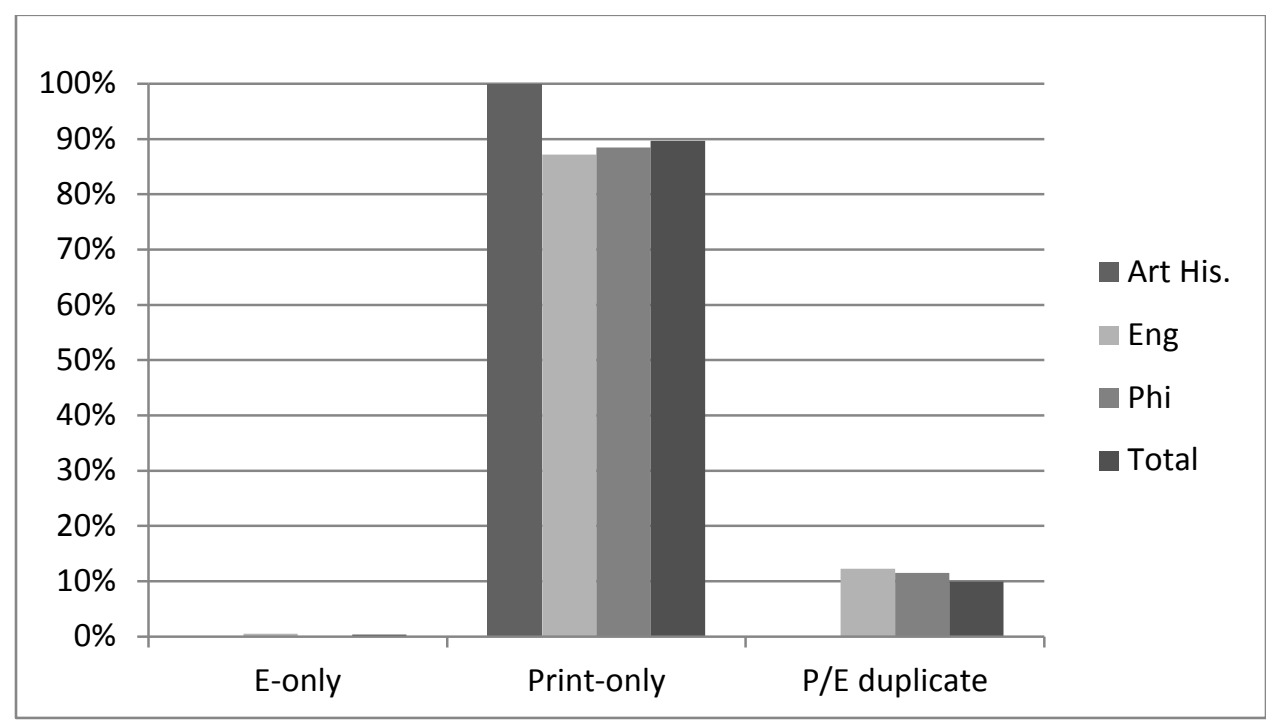

The publisher with the most cited items in the humanities was Routledge, with 25 titles (8\%).

\section{Humanities Analysis: Journals}

From the overall sample of 465 humanities citations, there were 124 journal articles cited (27\%). The average publication date of journal articles was 1983, with a median date of 1997. The average publication date for journals was three years older than books.

KU provided access to 115 of the 124 articles cited by humanities faculty (93\%). Of these, $62 \%$ were available in both electronic and print formats, with $17 \%$ available only in electronic format and $21 \%$ only in print (see Chart 9).

\section{Chart 9: Humanities Journal Access by Format (\%)}

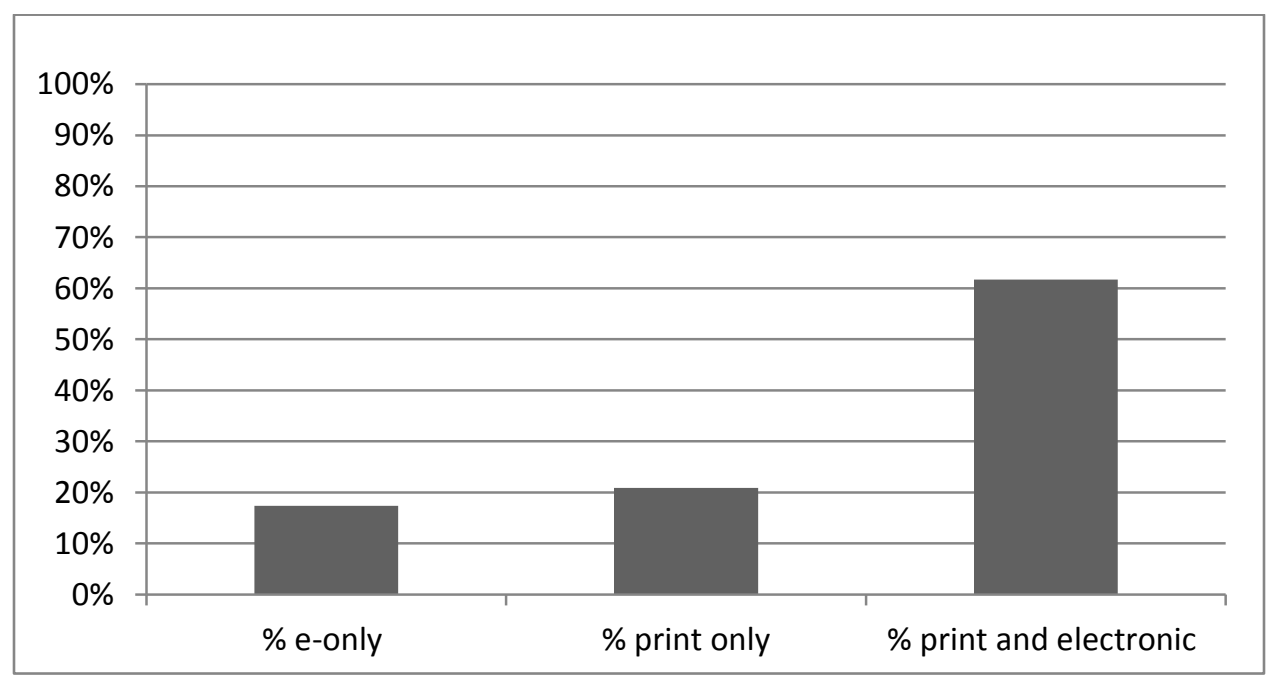


Of the articles available electronically, 44\% were available through a journal package and $66 \%$ were available through one or more aggregator databases. The publishers with the most citations were Wiley-Blackwell and Sage, with a combined total of $16(13 \%)$.

\section{Humanities Analysis: Format Usage}

While the overall ratio of books to journal usage in the humanities shows that books are more often used, philosophy cited journals more frequently than books (see Chart 10).

\section{Chart 10: Format Citations by Humanities Discipline (\%)}

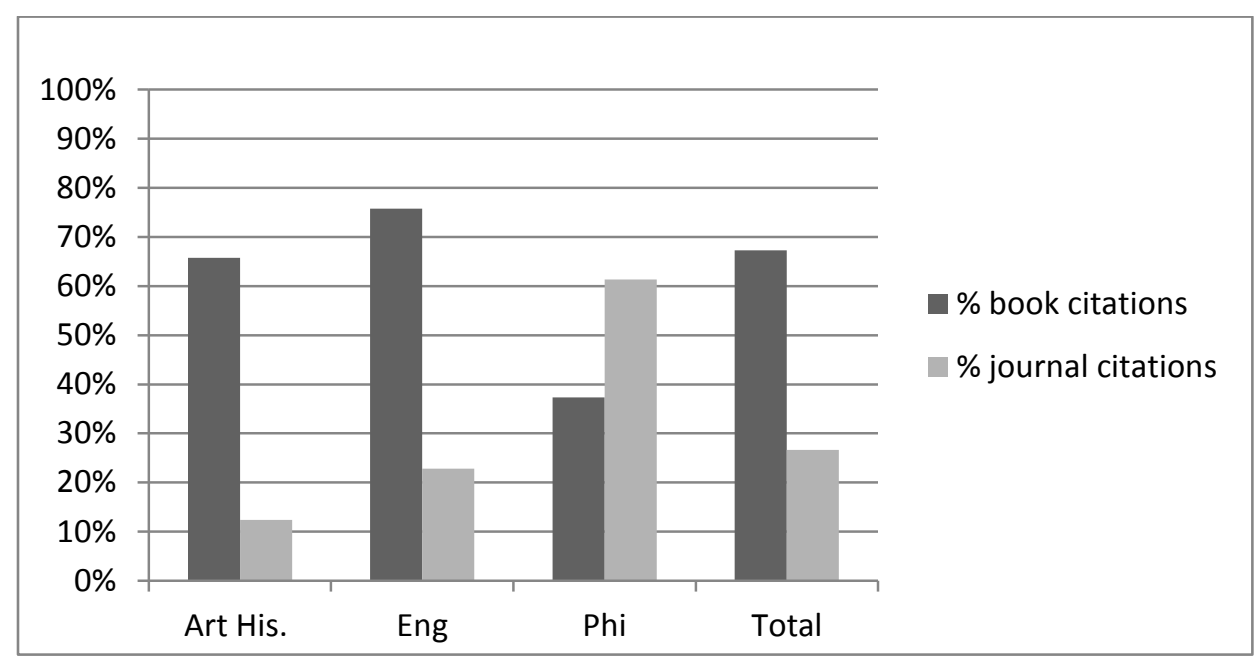

\section{Humanities Analysis: Items Not Held by KU}

KU did not provide access to $71(15 \%)$ of items cited by humanities faculty. Of these 71 items, $46(65 \%)$ are book citations, with $9(13 \%)$ journal articles not available through KU.

\section{Science/Technology Analysis}

For the science portion of the study, the three disciplines analyzed were: ecology and evolutionary biology, geology, and physics. The sample size was 1,511 out of 10,294 total citations, resulting in a $15 \%$ sample rate (see Table 3 ). This is a smaller sample percentage than both the social sciences and humanities because of the much larger number of citations and the time limitations of the study. This study has confirmed that scientists do cite significantly more resources per publication than researchers in other disciplinary areas. The average publication date of the science citations was 1992, with a median publication date of 2000. One difference among the samples of the science citations versus the other two areas is that the three science disciplines were almost equally represented. 
Table 3: Total Sample Citations by Discipline

\begin{tabular}{|l|l|l|l|}
\hline & EEB & Geology & Physics \\
\hline $\begin{array}{l}\text { Total Sample } \\
\text { Citations for } \\
\text { Analysis }\end{array}$ & 493 & 471 & 547 \\
\hline $\begin{array}{l}\text { \% of Citations in } \\
\text { Cumulative Sample }\end{array}$ & $33 \%$ & $31 \%$ & $36 \%$ \\
\hline
\end{tabular}

Overall, KU provided access to $85 \%$ of the total citations within the science sample. Within this study, $77 \%$ of the citations analyzed were from journal articles, while only $18 \%$ were from books. The remaining 5\% of citations fell into the "other" category, which consists of working papers, conference proceedings, reports, and more.

\section{Science Analysis: Books}

Out of the total 1,394 citations analyzed for this study, 245 were book citations (18\%). KU provided access to $172(70 \%)$ of these titles. As with the other broad disciplines analyzed, print was still the dominant access format for books. Eighty five percent of the KU-held titles were available in print only, with $9 \%$ available in e-only and $6 \%$ with print and electronic duplication. KU owns the largest number of e-only books in physic (9) and did not have any duplicate coverage of these titles (See Chart 11).

\section{Chart 11: Book Access by Format (\%)}

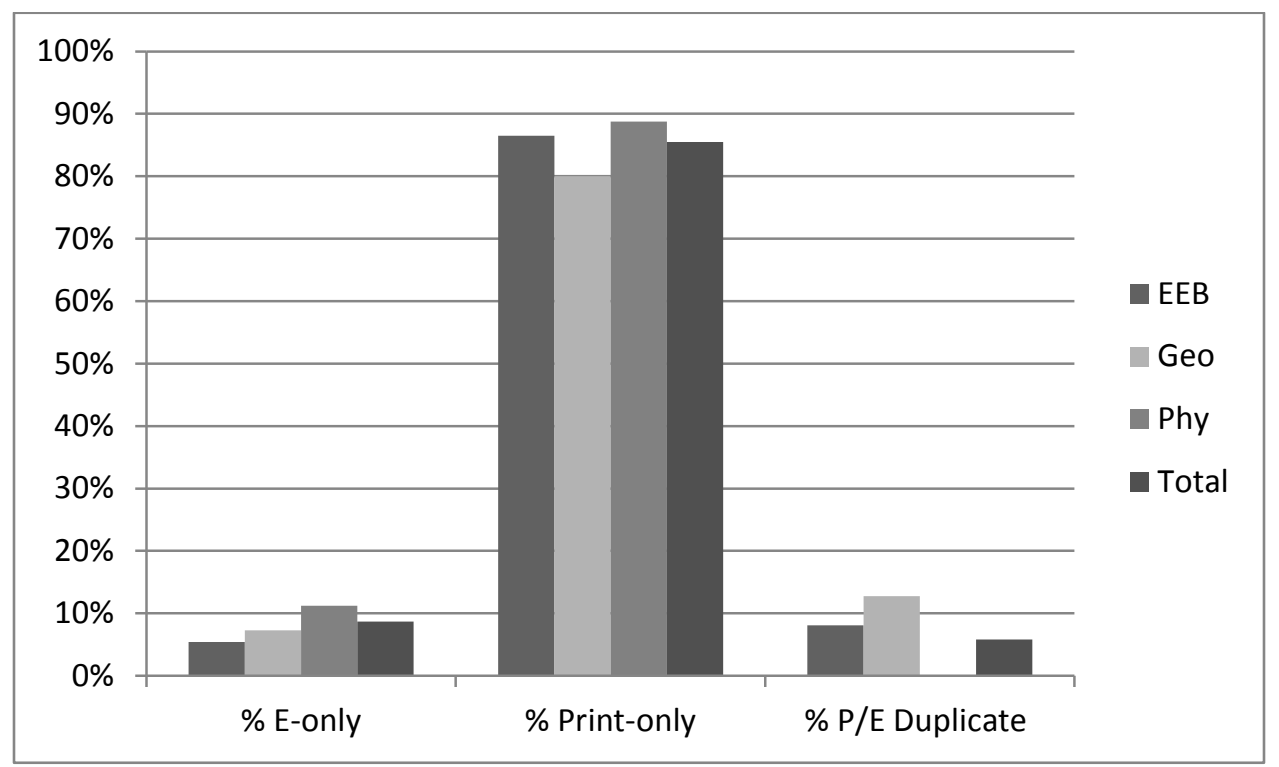


The publishers with the most cited items in the sciences were Cambridge University Press and Wiley-Blackwell, with a combined total of 18 citations or $17 \%$ of the total science books citations.

\section{Science Analysis: Journals}

From the overall science sample of 1,511 citations, 1,163 were journal articles (77\%). The average publication date was 1993 , with a median publication date of 2000 . KU provided access to $1,057(91 \%)$ of all journal articles cited by science faculty (see Chart 12).

\section{Chart 12: Journal Access by Format (\%)}

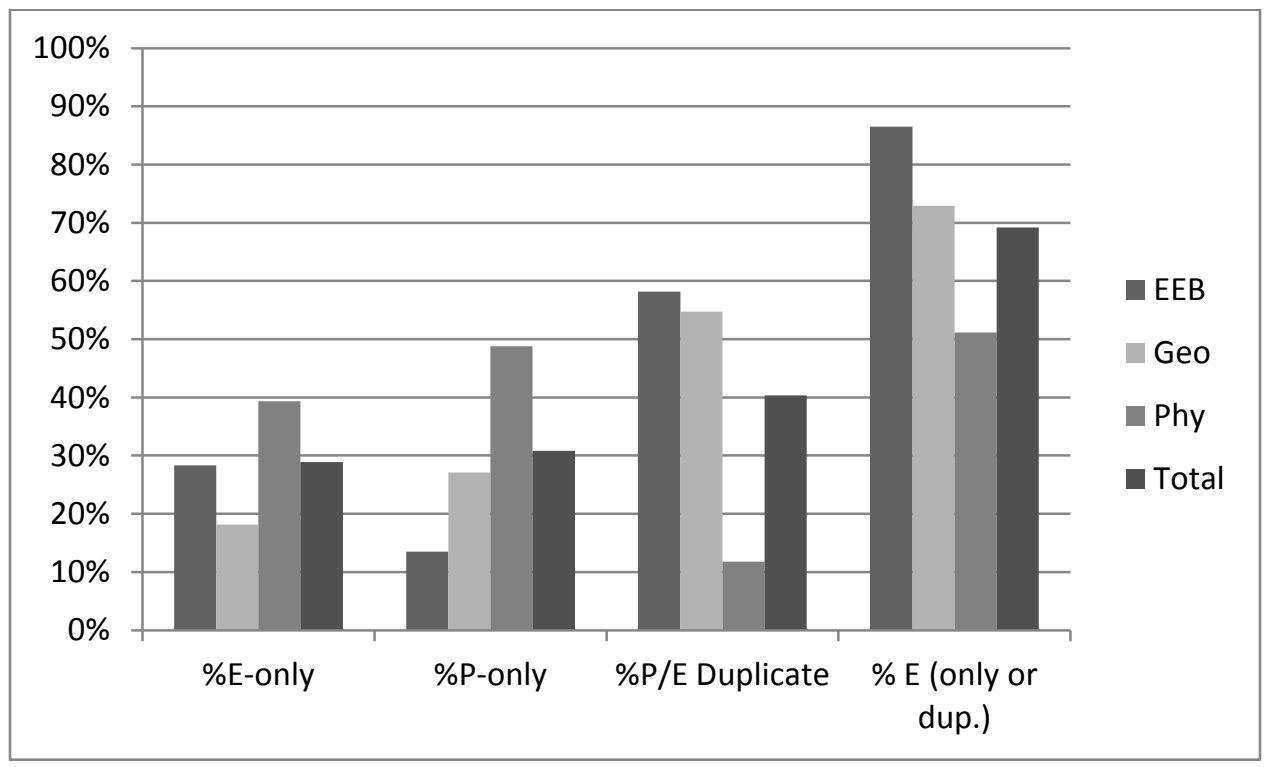

For articles available electronically, 75\% were available through a journal package and 30\% were available through one or more aggregator databases. The predominant journal publishers represented in the science journal citations are Elsevier (12\%) and Wiley-Blackwell (10\%).

\section{Science Analysis: Format Usage}

The results of this study show that researchers in all three science disciplines use journals at a much higher rate than books in research (see Chart 13). There is not a significant difference among the three disciplines, potentially demonstrating more homogeneity of citation patterns in the sciences than in the humanities or social sciences. 


\section{Chart 13: Format Usage by Science Disciplines (\%)}

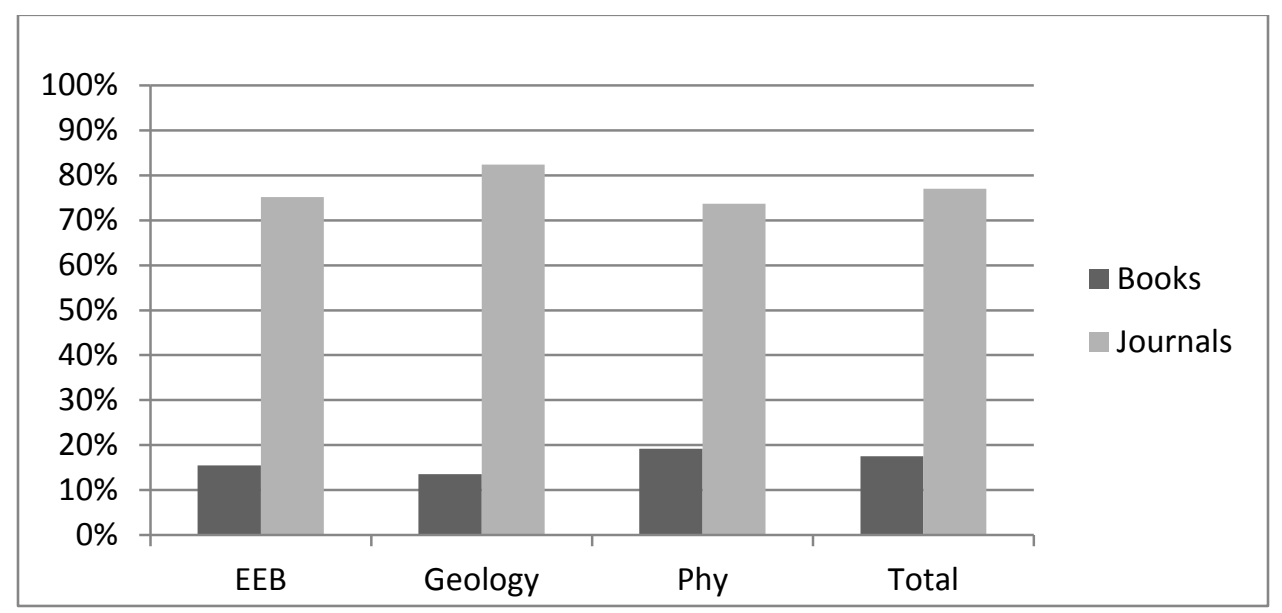

\section{Science Analysis: Items Not Held by KU}

KU did not provide access to 227 items cited by science faculty members (15\%). There were 73 books not held by KU (32\%). The average publication date of items not held by KU was 1985, with a median of 1996.

\section{Benchmarking}

The authors analyzed 20 citation studies in order to establish benchmarks for KU holdings (See Appendix). There are limitations to this approach because of differing methodologies and the dissimilar or inconsistent information reported in each study (see Table 4). Benchmarking for holdings and citation patterns across college and university libraries is an area of research that is lacking, but it is becoming increasingly more important to track the similarities and differences among academic libraries. Despite the limitations, the authors believe that a general picture of library holdings and citations can be documented so that a context is established to better evaluate KU holdings through external benchmarking.

Table 4: Benchmarking Articles

\begin{tabular}{|l|r|l|r|}
\hline Subject Areas Analyzed & & Author Group & \\
\hline Science & 10 & Dissertation/Theses & 11 \\
\hline Multi-disciplinary & 5 & Faculty & 6 \\
\hline Social Sciences & 3 & UG/Grad & 1 \\
\hline Humanities & 2 & Undergraduate & 1 \\
\hline & & Fac/Grad & 1 \\
\hline
\end{tabular}




\section{Comparison of Overall Holdings}

Of the 20 studies analyzed, nine studies reported overall local library holdings of references cited. After analyzing the available data, the authors determined that KU's holdings overall, and by disciplinary area, are higher than the average percent held by the other libraries (see Chart 14).

\section{Chart 14: Cumulative Study Analysis \& KU Study Holdings by Discipline (\%)}

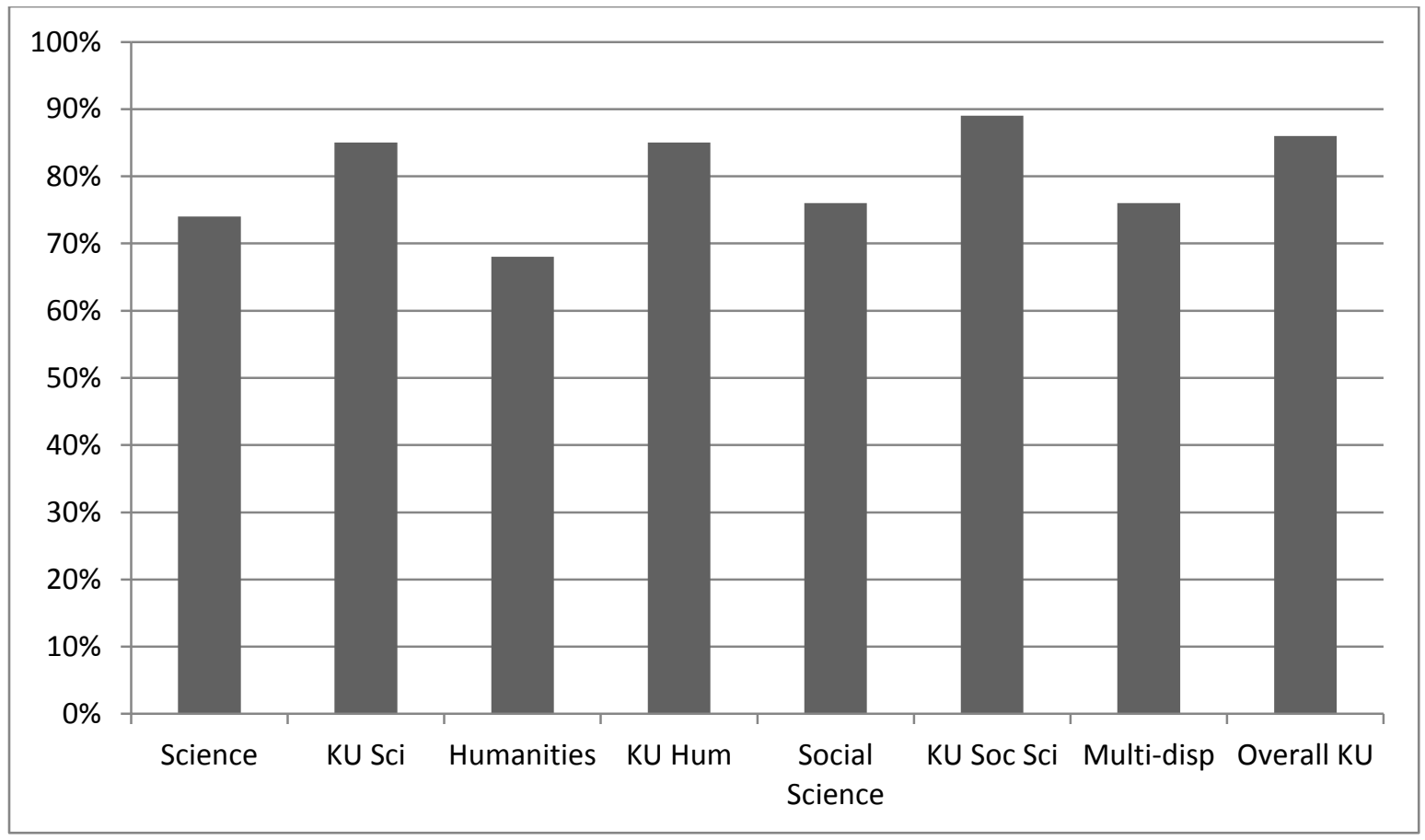

When comparing the different types of author groups, KU still holds higher percentages of cited items than the combined averages of the citation studies. However, the holdings percentages among the combined faculty studies and the KU study are similar (see Chart 15).

\section{Chart 15: \% Owned by Author Group and Format (\%)}

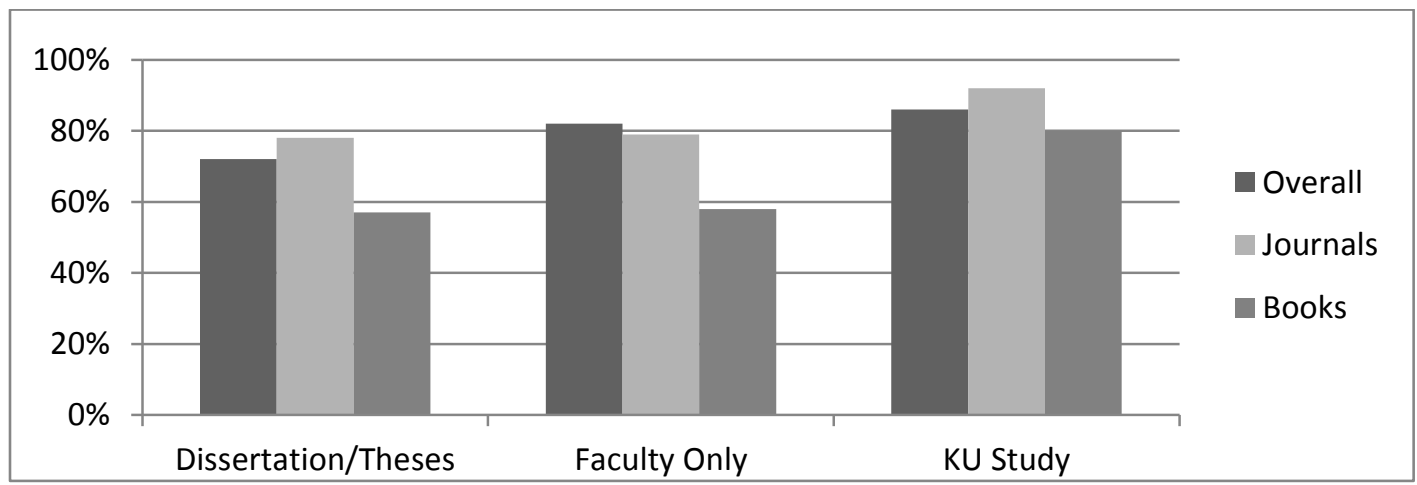




\section{Format Usage}

One indicator in which $\mathrm{KU}$ is comparable with other schools is in the reporting of format usage of authors. The average results of the analyzed citation studies reporting on the number of books and journal articles, show results similar to those in the KU study (see Chart 16).

\section{Chart 16: Format Usage (\%)}

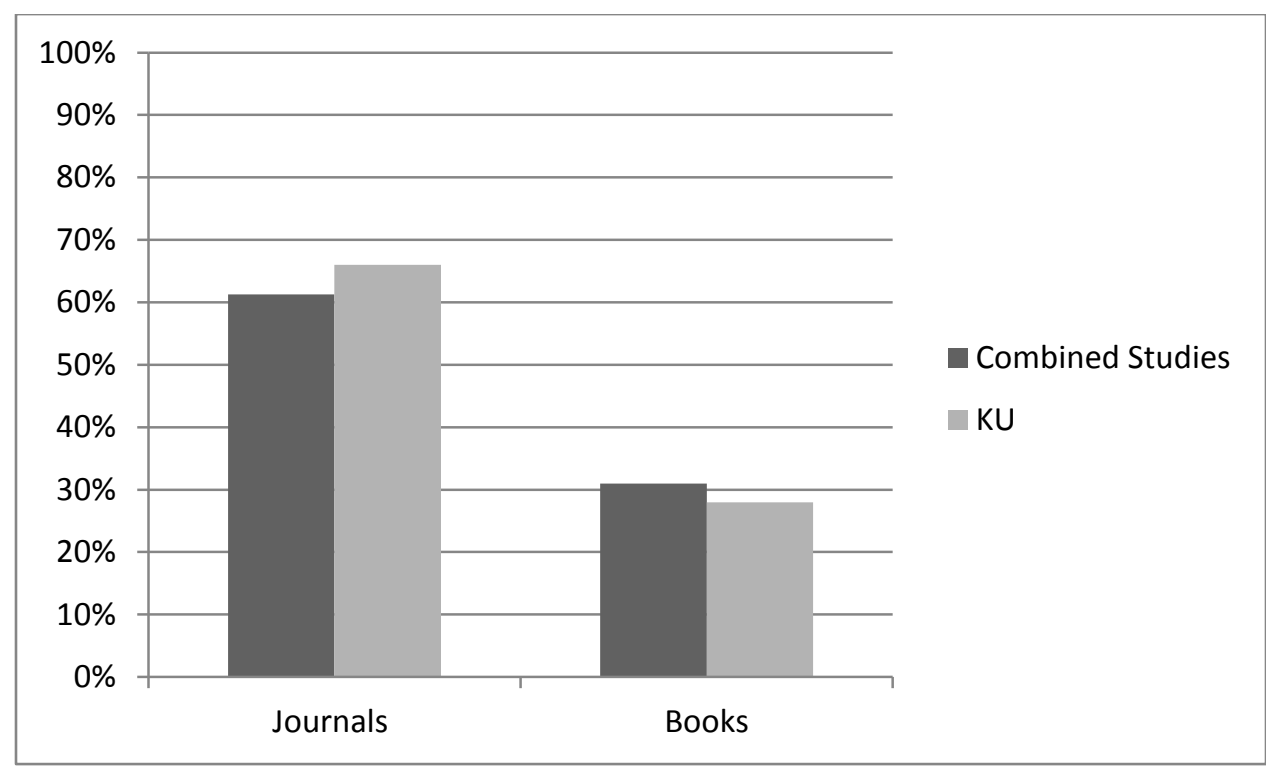

\section{Comparison of Overall Holdings}

Of the 20 studies analyzed, nine studies included overall local library holdings of references cited. From the available data, KU's holdings overall, and by disciplinary area, are higher than the average percent held by the other libraries (see Chart 17).

\section{Chart 17: Cumulative Study Analysis \& KU Study Holdings by Discipline (\%)}

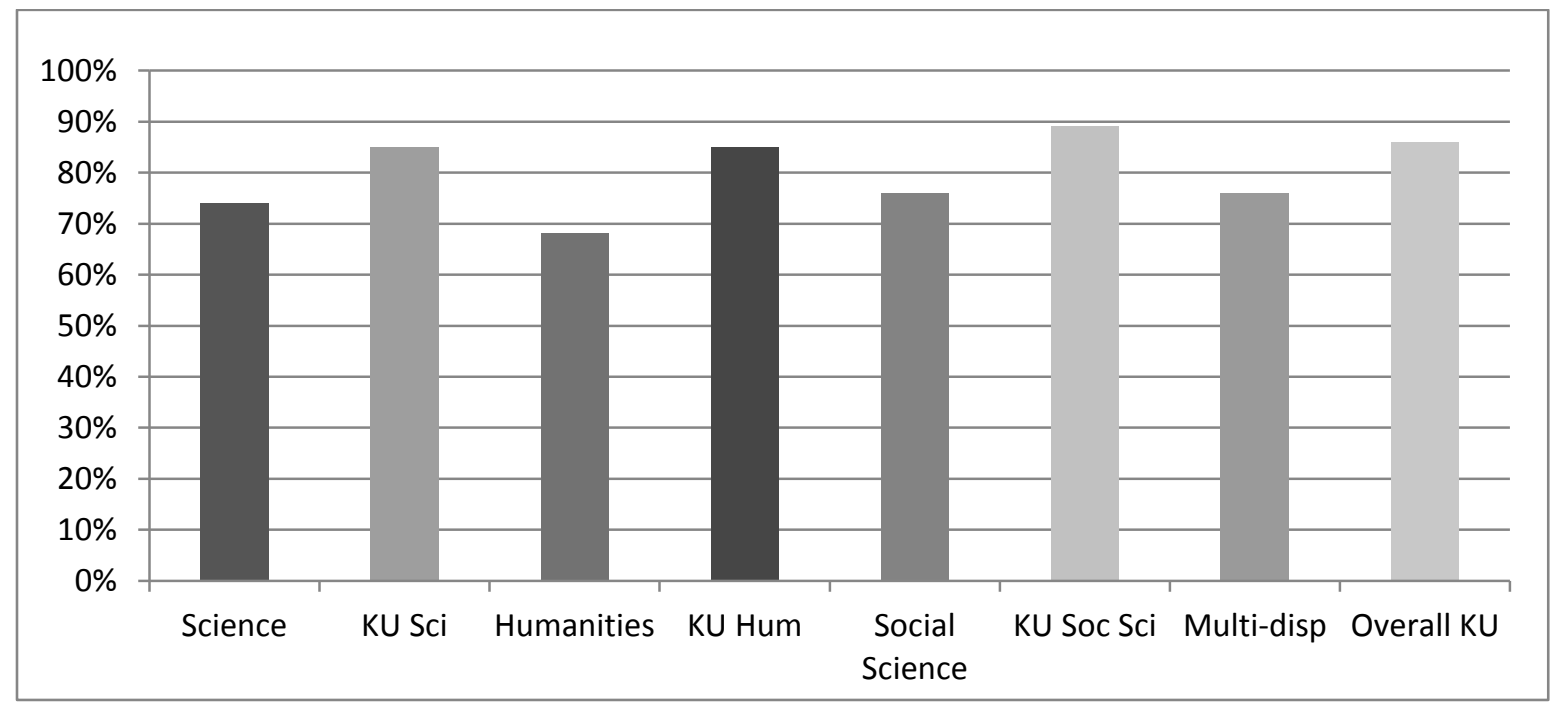


When comparing the different types of author groups, KU holds higher percentages of cited items than the combined averages of the studies (see Chart 18). However, the holdings percentages between the combined faculty studies and the KU study are the most similar.

Chart 18: \% Owned by Author Group and Format (\%)

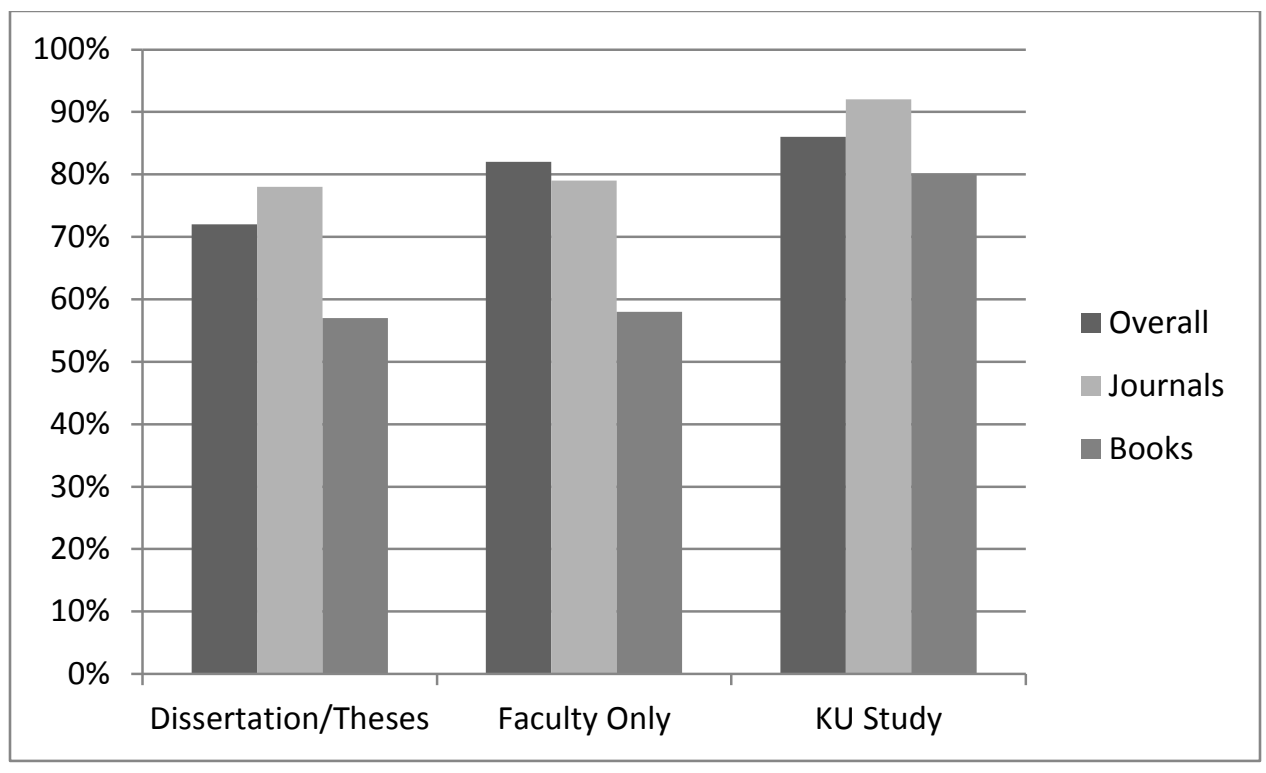

Overall, the comparisons of the KU study to other citation analysis articles demonstrate that $\mathrm{KU}$ is providing the equivalent or higher access to the resources that are cited in faculty publications. In addition, KU faculty citation patterns are similar to both faculty and graduate student citations at other universities, confirming the authors' original assumptions. This type of benchmarking goes beyond simply counting the number of books held, which is the standard approach to judging the quality of a library's collections. However, as the need for accountability in higher education increases, demonstrating impact is necessary and this cannot be achieved by simply counting inputs and outputs.

\section{Discussion and Conclusions}

The KU Libraries is currently undergoing a transition in resource selection models. With the advent of e-preferred purchasing in the sciences and social sciences, access to e-books is expanding. Librarians at KU have not chosen to go e-preferred for the humanities, but edited volumes are often purchased as e-books in the humanities. This would explain why, while there is still a small number, there are more e-books in the sciences and social sciences.

KU librarians have made a shift to selecting books in the sciences and social sciences to loading records into the library catalog as a demand-driven acquisition model. KU librarians 
have also considered loading records for books into the library catalog for demand-driven acquisitions for both of these broad disciplines instead of receiving books on approval. Given the relatively high use of books by the social scientists, demand-driven acquisition will be reconsidered in this area. .

When analyzing the call number ranges for the books and journals cited in faculty publications, this study concludes that while the sciences and social sciences cite mainly in their respective subject areas, the humanities often cite research from non-humanities disciplines (see Charts 19, 20, \& 21). For example, philosophy faculty cited from resources primarily in the social sciences. Citations in English included studies on gender, historical resources on the prison system in Australia, Victorian era women writers, migrant workers, and more.

Chart 19: \% of Social Science Journal \& Book Citations by Call Number Range

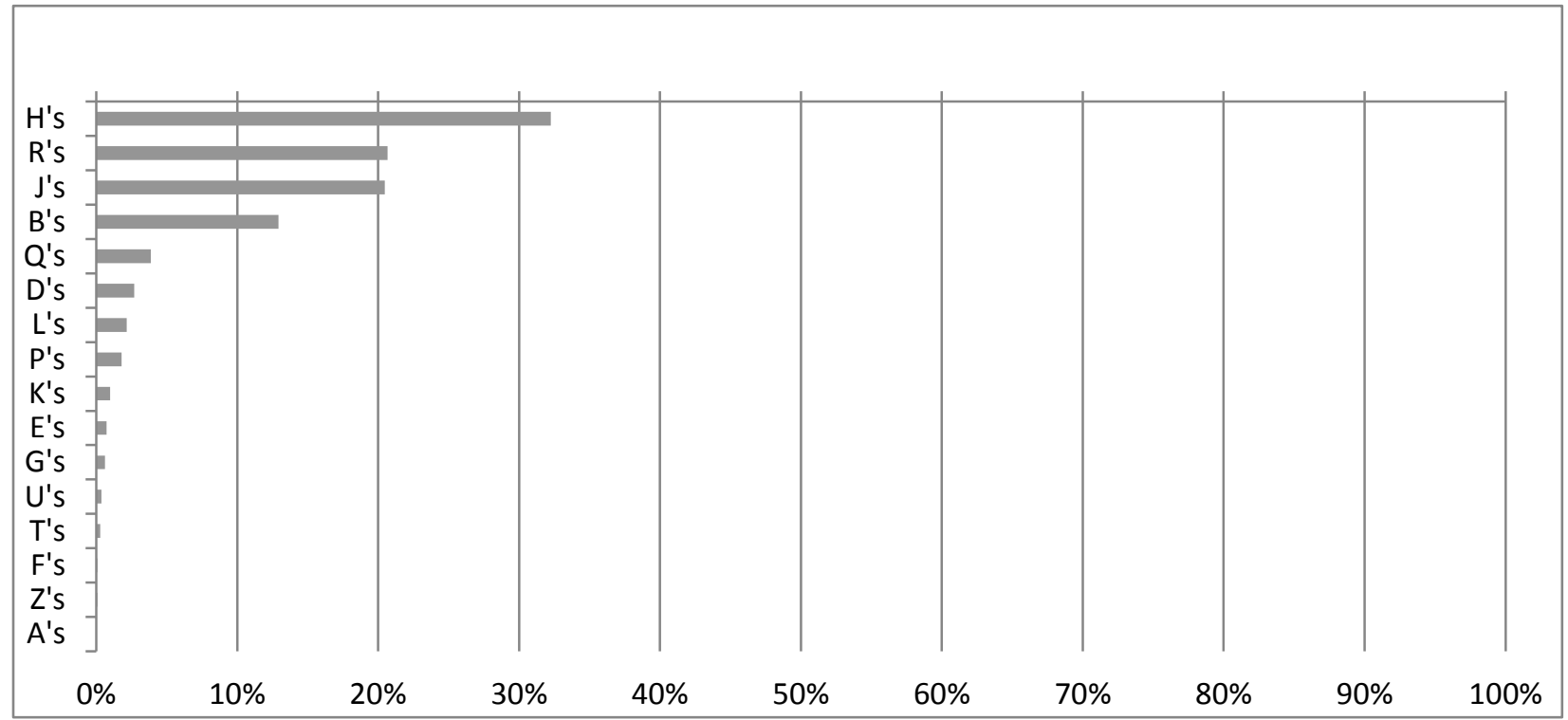

Chart 20: \% of Science Journal and Book Citations by Call Number Range

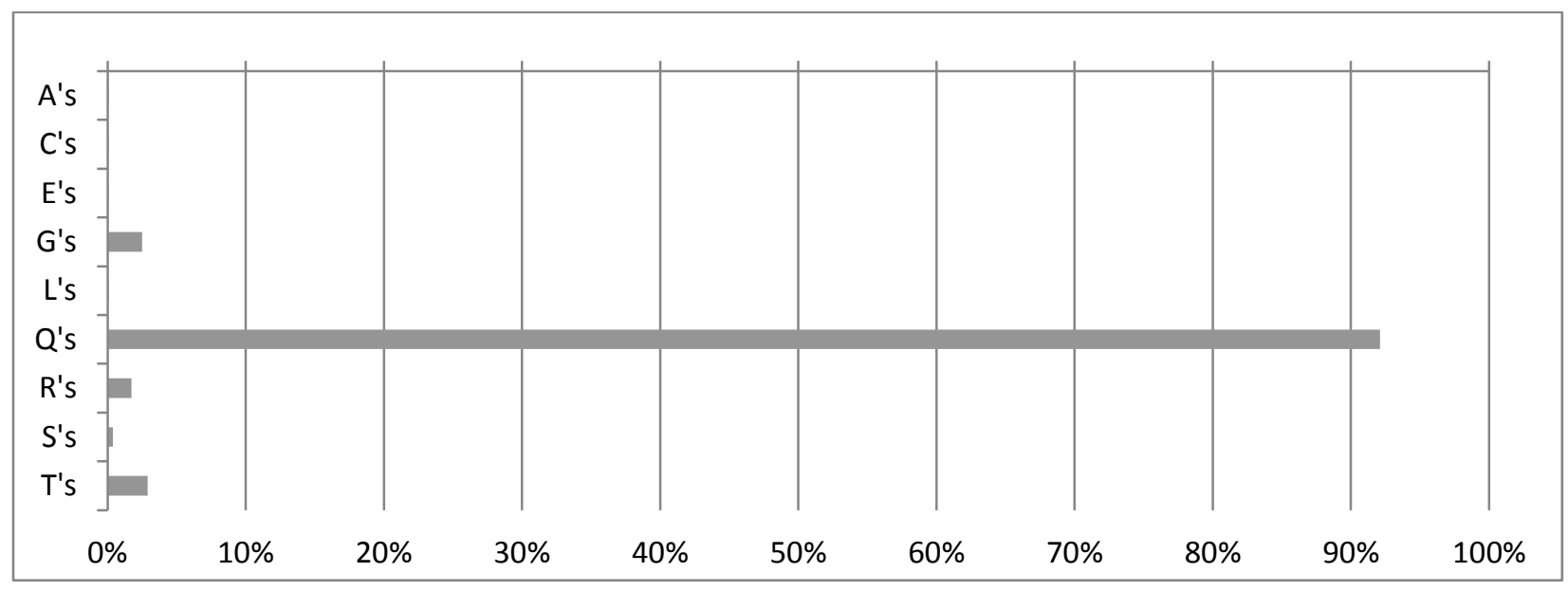




\section{Chart 21: \% of Humanities Journal \& Book Citations by Call Number Range \& Discipline}

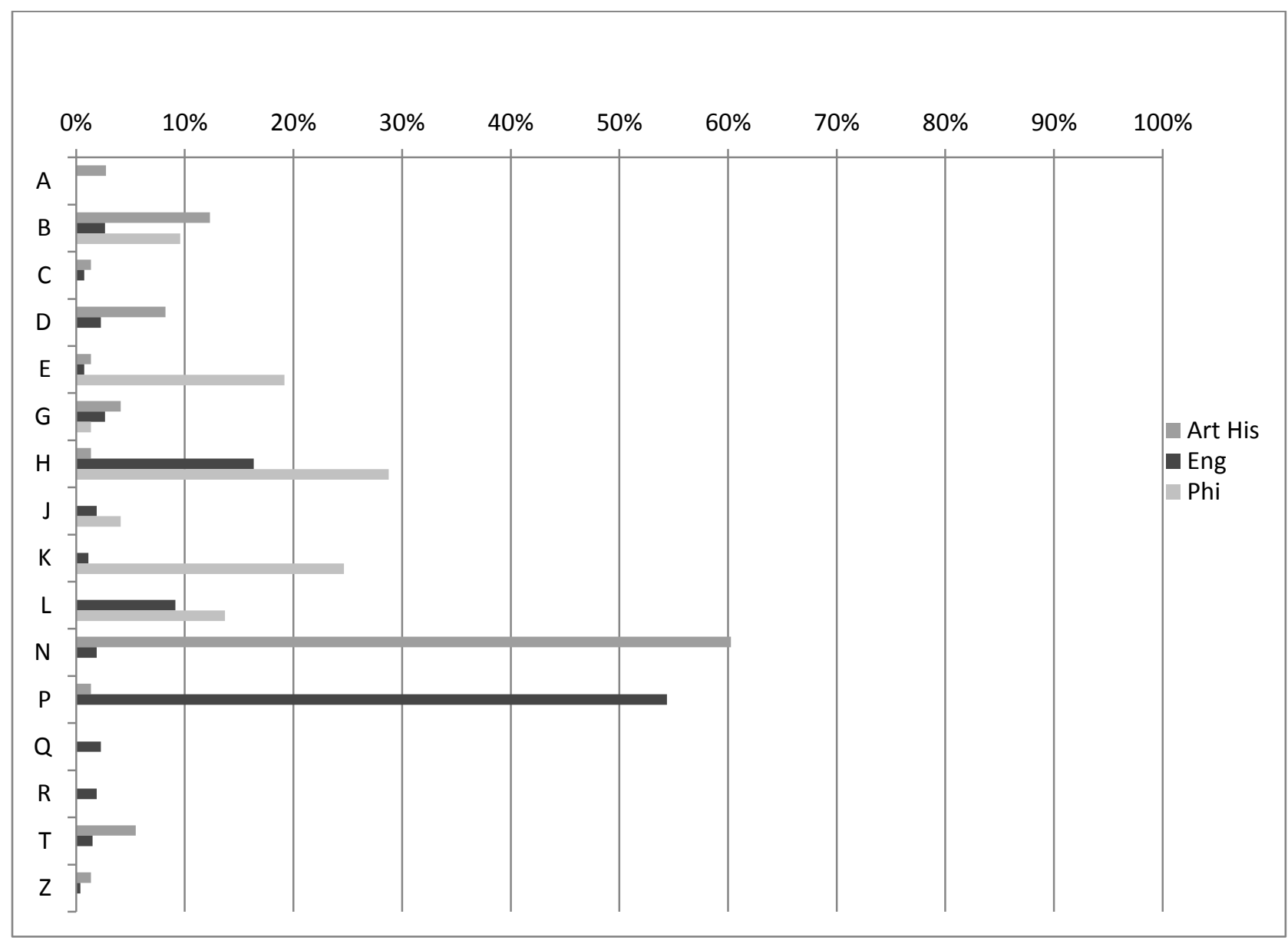

The most cited publishers were Cambridge University Press, Oxford University Press, Elsevier, and Wiley-Blackwell. While KU provides access to the most important publishers, the two publisher types that are lacking at $\mathrm{KU}$ are university presses and society or association presses. Combined, these two categories make up $20 \%$ of the journals and books cited by faculty. This is a potential area for further review related to purchasing decisions. Another weakness noted by the authors is the relatively high number of books in the sciences not held in the KU libraries (30\%). This is a high number compared to the social sciences and humanities and, given that most of the books published in the sciences fall in the $\mathrm{Q}$ call number range, another potential area for review is the purchasing patterns in this call number range.

Many assumptions made by the authors were confirmed. For instance, the science faculty cite more journals than books, while the humanities faculty cite more books than journals. At the same time, the authors were amazed that the resources cited by science faculty were older than expected, leading them to believe that collecting deep backfiles of journals and retaining older books in the collection is important. The authors were also surprised by the high 
number of books cited in the social sciences, particularly political science, whose faculty cited more books than journal articles.

Sixty percent of the KU Libraries' collection budget is spent on electronic resources, so the authors were relieved to find that subscription journal packages and aggregator databases do provide significant access to the journal articles needed by KU faculty. In the social sciences, $59 \%$ of the articles are accessed through journal packages and $45 \%$ through aggregator databases. In the humanities, $44 \%$ come for journal packages and $66 \%$ come from aggregators. The numbers in the humanities are especially surprising to the authors, who did not expect to find that humanities journals are primarily supplied by packages and aggregators. The sciences are also strongly supported by packages, but not as strongly by aggregators compared to the other areas. Seventy five percent of science journals come from journal packages, while $30 \%$ come from aggregators.

The authors found the citation analysis method of analyzing their collections extremely informative and look forward to expanding their study. To provide data that proves the value of library collections in supporting research at the university, the authors plan to expand their research by collecting citations from grant proposals submitted by KU research centers to check against KU library holdings. Another useful expansion of this research would be to analyze citations from older publications to see if format use, primarily books and journals, has evolved over time. The authors are also interested in determining the number of cited sources that come from journals available in open access repositories and monitoring the anticipated increase in these citations over time. Finally, an expanded benchmarking project would also prove beneficial for understanding local holdings within an external context that goes beyond simple holding counts. Overall, the possibilities of expanding citation analysis research studies are limitless.

\section{Appendix: Benchmarking Studies}

Choinski, E. M. (2007). Journal use in pharmacy: A citation analysis of faculty publications at a school of pharmacy. Science \& Technology Libraries, 27(3), 53-64.

deVries, S., Kelly, R., \& Storm, P. M. (2010). Moving beyond citation analysis: how surveys and interviews enhance, enrich, and expand your research findings. College \& Research Libraries, 71(5), 456-466.

Feyereisen, P., \& Spoiden, A. (2009). Can local citation analysis of master's and doctoral theses help decision-making about the management of the collection of periodicals? A case study in psychology and education sciences. The Journal of Academic Librarianship, 35(6), 514-522. 
Fuchs, B. E., Thomsen, C. M., Bias, R. G., \& Davis, D. G. (2006). Behavioral citation analysis: toward collection enhancement for users. College \& Research Libraries, 67(4), 304-324.

Iivonen, M., Nygrén, U., Valtari, A., \& Heikkilä, T. (2009). Library collections contribute to doctoral studies: citation analysis of dissertations in the field of economics and administration. Library Management, 30(3), 185-203.

Kayongo, J., \& Helm, C. (2012). Relevance of library collections for graduate student research: A Citation analysis study of doctoral dissertations at Notre Dame. College \& Research Libraries, 73(1), 47-67.

Kellsey, C., \& Knievel, J. (2012). Overlap between humanities faculty citation and library monograph collections, 2004-2009. College \& Research Libraries, 73(6), 569-583.

Kuruppu, P. U., \& Gruber, A. M. (2006). Understanding the information needs of academic scholars in agricultural and biological sciences. The Journal of Academic Librarianship, 32(6), 609-623.

Leiding, R. (2005). Using citation checking of undergraduate thesis bibliographies to evaluate library collections. College and Research Libraries, 66, 417-429.

Nabe, J., \& Imre, A. (2008). Dissertation citations in organismal biology at Southern Illinois University at Carbondale: Implications for collection development. Issues in Science and Technology Librarianship (55), 8.

Omoba, F. A., \& Fabunmi, B. A. (2010). Evaluation of references in dissertations and theses against the holdings in a university library. Library Philosophy and Practice (February).

Price, J. S. (2007). How many journals do we have? An alternative approach to journal collection evaluation through local cited article analysis. Serials: The Journal for the Serials Community, 20(2), 134-141.

Salisbury, L. \& Smith, J.S. (2010). The use of Web of Knowledge to study publishing and citation use for local researchers at the campus level. Collection Management, 35, 69-82.

Sherriff, G. (2010). Information use in history research: A Citation analysis of master's level theses. portal: Libraries and the Academy, 10(2), 165-183.

Smith, E. T. (2003). Assessing collection usefulness: an investigation of library ownership of the resources graduate students use. College \& Research Libraries, 64(5), 344-355.

Sylvia, M. J. (1998). Citation analysis as an unobtrusive method for journal collection evaluation using psychology student research bibliographies. Collection Building, 17(1), 20-28. 
Vallmitjana, N., \& Sabate, L. G. (2008). Citation analysis of Ph.D. dissertation references as a tool for collection management in an academic chemistry library. College \& Research Libraries, 69(1), 72-81.

Williams, V. K., \& Fletcher, C. L. (2006). Materials used by master's students in engineering and implications for collection development: a citation analysis. Issues in Science and Technology Librarianship, 45(Winter).

Wilson, C. S., \& Tenopir, C. (2008). Local citation analysis, publishing and reading patterns: Using multiple methods to evaluate faculty use of an academic library's research collection. Journal of the American Society for Information Science and Technology, 59(9), 1393-1408.

Wirth, A. A., \& Mellinger, M. (2011). Five years later: Predicting student use of journals in a new water resources graduate program. Issues in Science and Technology Librarianship (64), 1.

${ }^{\mathrm{i}}$ Hoffmann, K., \& Doucette, L. (2012). A review of citation analysis methodologies for collection management. College \& Research Libraries, 73(4), 321-335.

${ }^{\text {ii }}$ Watson, A. (2010). Tips for conducting citation analysis in an academic setting. Mississippi Libraries, 74(1), 14-16.

iii Choinski, E. M. (2007). Journal use in pharmacy: A citation analysis of faculty publications at a school of pharmacy. Science \& Technology Libraries, 27(3), 53-64.

${ }^{\text {iv }}$ LaBonte, K. (2005). Citation analysis: a method for collection development for a rapidly developing field. Issues in Science and Technology Librarianship, 43, http://www.istl.org/05-summer/refereed.html.

${ }^{v}$ Salisbury, L. \& Smith, J.S. (2010). The use of Web of Knowledge to study publishing and citation use for local researchers at the campus level. Collection Management, 35, 69-82.

${ }^{v i}$ Wilson, C.S. \& Tenopir, C. (2008). Local citation analysis, publishing, and reading patterns: using multiple methods to evaluate faculty use of an academic library's research collection. Journal of the American Society for Information Science and Technology, 59, 1393-1408. 


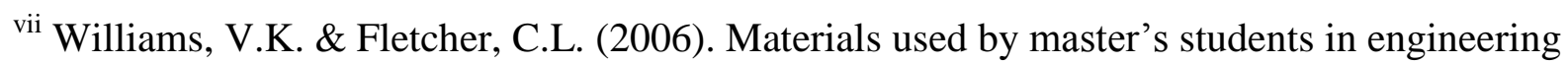
and implications for collection development: a citation analysis. Issues in Science and Technology Librarianship, 45 (Winter).

viii Kuruppu, P. U., \& Gruber, A. M. (2006). Understanding the information needs of academic scholars in agricultural and biological sciences. The Journal of Academic Librarianship, 32(6), 609-623.

${ }^{\text {ix }}$ Vallmitjana, N., \& Sabate, L. G. (2008). Citation analysis of Ph.D. dissertation references as a tool for collection management in an academic chemistry library. College \& Research Libraries, 69(1), 72-81.

${ }^{\mathrm{x}}$ Feyereisen, P., \& Spoiden, A. (2009). Can local citation analysis of master's and doctoral theses help decision-making about the management of the collection of periodicals? A case study in psychology and education sciences. The Journal of Academic Librarianship, 35(6), 514-522.

${ }^{x i}$ Fuchs, B.E., Thomsen, C.M., Bias, R.G., \& Davis, Jr., D.G. (2006). Behavioral citation analysis: toward collection enhancement for users. College and Research Libraries, 67, 304-324.

${ }^{x i i}$ Smith, E.T. (2003). Assessing collection usefulness: an investigation of library ownership of the resources graduate students use. College and Research Libraries, 64, 344-355.

xiii Kayongo, J., \& Helm, C. (2012). Relevance of library Collections for graduate student research: A Citation analysis study of doctoral dissertations at Notre Dame. College \& Research Libraries, 73(1), 47-67.

${ }^{\text {xiv }}$ Leiding, R. (2005). Using citation checking of undergraduate thesis bibliographies to evaluate library collections. College and Research Libraries, 66, 417-429. 